\title{
Cavernous Lymphangiomas of the Breast Mimicking Breast Cancer
}

Kyung Hee Ko, MD, Eun-Kyung Kim, MD, Hye Yoon Kang, MD, Ji Hyun Youk, MD

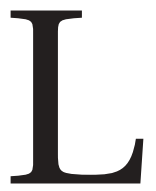

ymphangiomas are congenital malformations of the lymphatic system and are thought to result from failure of the lymphatic system to connect with the venous system. Lymphangiomas in the breast are rare entities, and only a few cases have been documented in the literature. ${ }^{1,2}$ Its sonographic appearance is reported as similar to that of a cluster of simple cysts or dilated ducts; however, the echogenicity depends on the size of the lymphatic channels, similar to a hemangioma. Here, we report a case of breast lymphangiomas mimicking multifocal breast cancer in a 34-year-old woman.

Received January 19, 2009, from the Departments of Radiology (K.H.K., J.H.Y.) and Pathology (H.Y.K.), Bundang CHA Hospital, Pochon CHA University, Seongnam, Korea; and Department of Radiology, Research Institute of Radiological Science, Yonsei University College of Medicine, Seoul, Korea (E.K.K.). Revision requested February 20, 2009. Revised manuscript accepted for publication March 12, 2009.

Address correspondence to Eun-Kyung Kim, MD, Department of Radiology, Yonsei University College of Medicine, Seodaemun-ku, Shinchondong 134, Seoul 120-752, Korea.

E-mail: ekkim@yuhs.ac

\section{Case Report}

A 34-year-old woman came to our hospital with a 2month history of a palpable mass in her left breast. Physical examination revealed a movable nontender mass located in the upper outer quadrant and another soft mass measuring $1.5 \mathrm{~cm}$ located in the left axilla. The overlying skin was not remarkable. She had undergone simple excision of a benign mass in the left axilla 10 years previously. We performed sonography first because of her young age. On sonography, the palpable mass in the left upper outer breast was revealed as an irregular spiculated hypoechoic mass with a central cystic portion (Figure 1A). Another poorly defined oval complex echoic mass was also in the same quadrant (Figure 1B). There was no axillary lymphadenopathy, but there was a well-defined cystic mass in the left axillary palpable portion mimicking dilated ducts in accessory breast tissue (Figure 2). Poorly defined masses located in the left upper outer quadrant were sonographically suspicious for breast cancer, and sonographically guided core biopsies were performed for each mass. The pathologic diagnosis was lymphangiomas. Surgical excision was performed after sonographically guided localization of the breast lesions. The axillary mass was not excised, and it was presumed to be recurrent lymphangiomas after the previous surgery. 


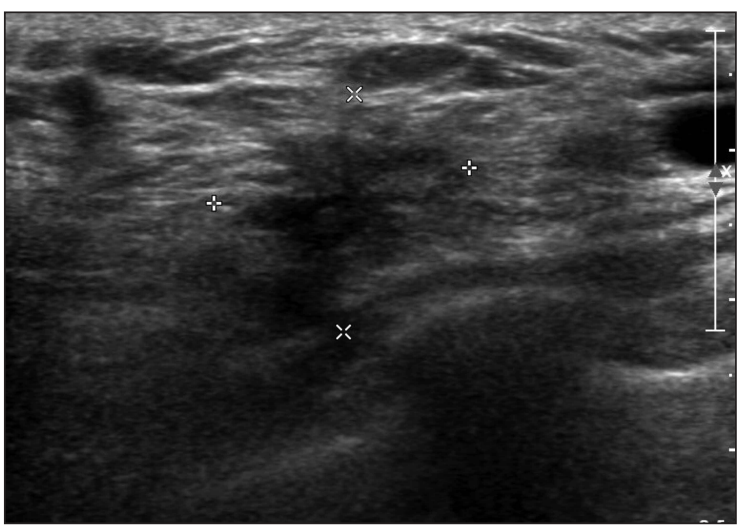

A

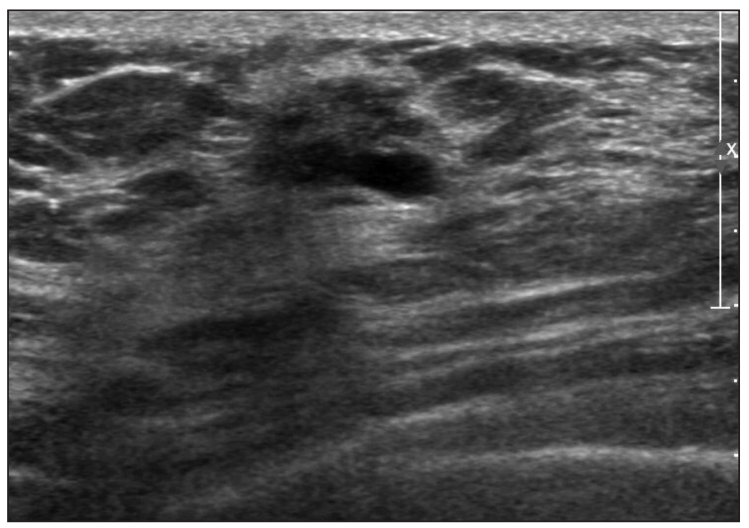

B

Figure 1. A, Transverse sonogram of a palpable mass in the left upper outer quadrant of the breast showing an irregularly shaped hypoechoic mass suspicious for malignancy (American College of Radiology Breast Imaging Reporting and Data System category 4). B, Transverse sonogram of another mass located in the same quadrant showing an oval complex echoic mass with a spiculated margin suspicious for malignancy (Breast Imaging Reporting and Data System category 4).

Gross pathologic examinations revealed poorly defined spiculated whitish gray masses. Microscopically, they were composed of numerous cavernous and cystically dilated spaces lined by endothelial cells supported by a prominent fibrocollagenous stroma (Figure 3). The final histologic diagnosis was cavernous lymphangiomas of the breast.

\section{Discussion}

Lymphangiomas are relatively uncommon lesions, more so in the breasts, where they are very rare. They occur predominantly in children, with up to $90 \%$ of cases presenting by the second year of life. ${ }^{3}$ Lymphangiomas are vascular malformations rather than true neoplasms, and they are produced by sequestrated primitive lymphatic tissue that fails to communicate with peripheral drainage pathways. ${ }^{2-4}$ Lymph vessels of the adult mammary gland originate in the interlobular connective tissue and the walls of lactiferous ducts. They communicate with the overlying cutaneous lymphatic plexus around the nipple in the subareolar plexus and then drain to the axilla. ${ }^{5}$ Cases of lymphangiomas in the breast that have been reported in the literature have mainly been located in the upper outer quadrant of the breast. ${ }^{6-8}$ In our case, the same distribution pattern was seen. This result may be related to the drainage pattern of the breast lymphatic system.
The mammographic findings are nonspecific. Because of the frequent location high in the axilla, it may not be possible to image these lesions. Additionally, many occur in infants and children, in whom it is desirable to avoid radiation if possible. Cystic lymphangiomas show round or lobulated densities on mammography. ${ }^{9-11}$ When the lymphatic channels are prominent, the sonographic appearance can be similar to that of duct ectasia that occurs within accessory breast tissue within the axilla. The lymphatic vessels in a lymphangioma can be completely collapsed with transducer pressure, whereas the ectatic ducts within accessory breast tissue cannot. ${ }^{12}$

Figure 2. Sonogram of the left axilla showing a cystic mass mimicking dilated ducts in accessory breast tissue.

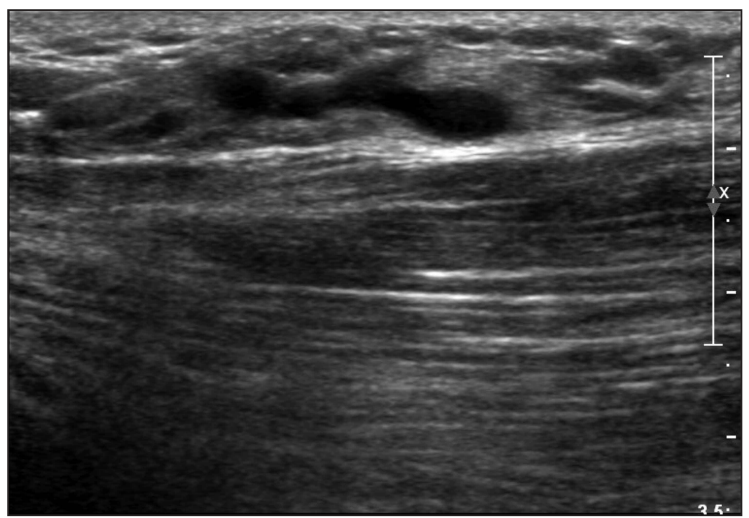




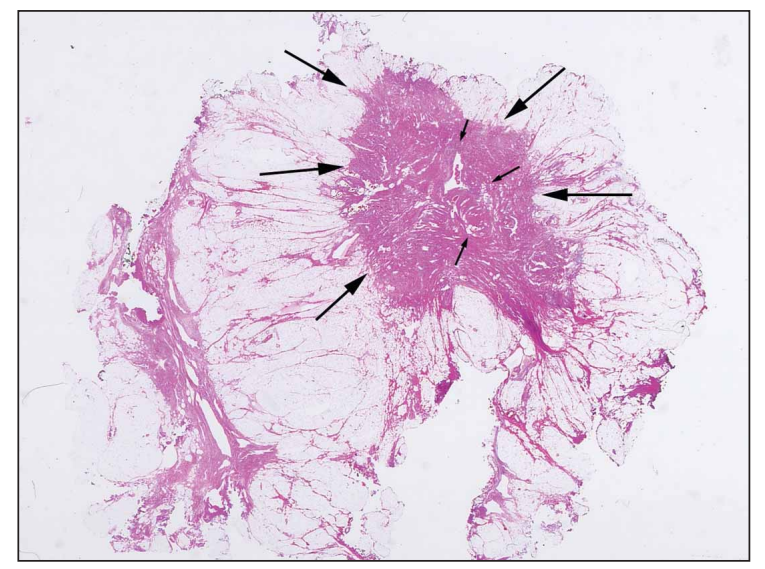

A

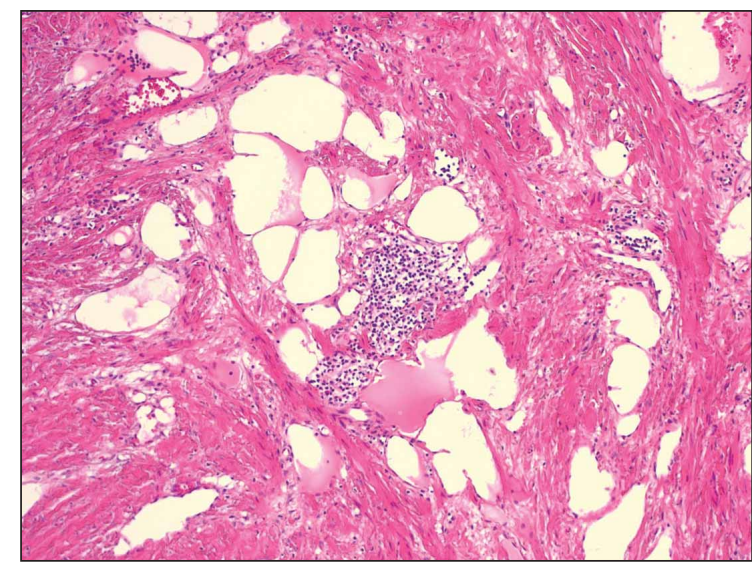

B

Figure 3. A, Pathologic section showing an excellent correlation with the sonographic appearance. The margin of the tumor is composed of extensive fibrosis with a fibrocollagenous stroma (large arrows). Note the small lymphatic channels in the center of the mass (small arrows). B, Microscopic appearance of the lymphangioma showing the dilated lymphatic channels lined by endothelial cells (hematoxylin-eosin, original magnification $\times 100$ ).

Usually, lymphangiomas are described as fairly well-defined multicystic masses. In our case, however, they appeared as complex echoic spiculated masses mimicking breast cancer. The echogenicity of lymphangiomas can change from the size of the lymphatic channels. When the lymphatic channels are small, the echogenic vessel walls are close together, making numerous interfaces, and the overall echogenicity resembles that of solid masses. In our case, the lymphatic channels were too small to make a well-defined cystic mass. In addition, extensive fibrosis with a prominent fibrocollageneous stroma in the periphery made the masses spiculated and hypoechoic.

Magnetic resonance imaging is the imaging modality of choice for diagnosis and evaluating the extent of disease. On magnetic resonance imaging, cystic lymphangiomas are typically seen as septated masses of low T1- and high T2weighted signal intensity, with only septal enhancement. The signal intensity of cyst contents can be variable because of hemorrhage or proteinaceous fluid. ${ }^{13}$

Primary treatment of lymphangiomas is surgical excision. However, there may be difficulty in obtaining safe margins because of the tendency of these lesions to infiltrate surrounding tissues. The probability of recurrence is low if the lesions are completely excised. ${ }^{14}$ Sometimes, percutaneous sclerosis or a combination of percutaneous sclerosis and surgical excision is performed.
This report describes an unusual case of cavernous lymphangiomas of the breast presenting as suspicious malignant masses from an extensive fibrocollagenous stroma and small lymphatic channels. Although the incidence of this disease is extremely rare in the adult breast, a breast lymphangioma should be considered when an irregular complex echoic cystic mass is located in the upper outer quadrant of the breast. Wide surgical excision after evaluation of the disease extent is the most effective treatment modality.

\section{References}

1. Sa EJ, Choi YH. Cystic lymphangioma of the breast. J Clin Ultrasound 1999; 27:351-352.

2. Chung SY, Oh KK, Kim DJ. Mammographic and sonographic findings of a breast cystic lymphangioma. J Ultrasound Med 2003; 22:307-309.

3. Singh S, Baboo ML, Pathak LC. Cystic lymphangioma in children: report of 32 cases including lesions at rare sites. Surgery 1971; 69:947-951.

4. Chervenak FA, Isaacson G, Blakemore KJ, et al. Fetal cystic hygroma. N Engl J Med 1983; 309:822-825.

5. Kangesu T. Cystic hygroma of the breast in childhood. Br J Clin Pract 1990; 44:787-788.

6. de Guerke L, Baron M, Dessogne P, Callonnec F, d'Anjou J. Cystic lymphangioma of the breast. Breast J 2005; 11:515-516

7. Min KH, Jang SH, Jang SM, Jun YJ, Jang KS, Paik SS. Cystic lymphangioma of the breast in an adult woman. Korean J Pathol 2008; 42:244-246. 
8. Sieber PR, Sharkey FE. Cystic hygroma of the breast. Arch Pathol Lab Med 1986; 110:353.

9. Shin HJ, Yun EJ, Lee JK, Kim JR. Cystic lymphangioma of breast: a case report. J Korean Radiol Soc 1995; 32:347-349.

10. Kook SH, Keum JS. Mammography, US, and MR findings of cystic lymphangioma of the breast: a case report. J Korean Radiol Soc 1996; 35:279-281.

11. Salvador R, Salvador M, Miranda D, Rull M, Lopez D. Cystic hygroma of the breast. Eur J Radiol 1990; 11:215-217.

12. Stavros AT. Breast Ultrasound. Philadelphia, PA: Lippincott Williams \& Wilkins; 2004.

13. Kuhlman JE, Bouchardy L, Fishman EK, Zerhouni EA. CT and MR imaging evaluation of chest wall disorders. Radiographics 1994; 14:571-595.

14. Ogun GO, Oyetunde O, Akang EE. Cavernous lymphangioma of the breast. World J Sur Oncol 2007; 5:69. 